\title{
NUCLEUS ACCUMBENS NEURONS ENCODE PAVLOVIAN APPROACH BEHAVIORS: EVIDENCE FROM AN AUTOSHAPING PARADIGM
}

\author{
Jeremy Jason Day
}

A thesis submitted to the faculty of the University of North Carolina at Chapel Hill in partial fulfillment of the requirements for the degree of Master of Arts in the Department of Psychology.

Chapel Hill

2007

Approved by:

Dr. Regina M. Carelli

Dr. Todd E. Thiele

Dr. Mitchell J. Picker 
(C) 2007

Jeremy Jason Day

ALL RIGHTS RESERVED 


\begin{abstract}
JEREMY DAY: Nucleus Accumbens Neurons Encode Pavlovian Approach Behaviors: Evidence from an Autoshaping Paradigm

(Under the direction of Regina Carelli)
\end{abstract}

Environmental stimuli predictive of appetitive events can elicit Pavlovian approach responses that enhance an organism's ability to track and secure natural rewards. We examined the activity of individual nucleus accumbens (NAc) neurons during the performance of approach behaviors. Animals were presented with conditioned stimuli that were either positive (the $\mathrm{CS}+$ ) or negative (the $\mathrm{CS}-$ ) predictors of reward. Approach responses directed at these cues were recorded as lever presses and were significantly more likely to occur during CS+ presentations. On the test day, $75 \%$ of NAc neurons exhibited changes in firing rate (termed 'phasically active') during CS+ presentations. Of these cells, $47 \%$ were characterized by time-locked increases in cell firing while $53 \%$ showed reductions in firing for the duration of the CS+. The same cells typically showed little or no change during CS- presentations. These results suggest that NAc neurons encode reward prediction and/or approach responses elicited by rewardpaired cues. 


\section{ACKNOWLEDGEMENTS}

I would like to thank Dr. Robert A. Wheeler and Dr. Mitchell F. Roitman for their

technical expertise and guidance and Jennifer M. Slater for technical assistance. This research was supported by NIDA DA14339 to RMC. 


\section{TABLE OF CONTENTS}

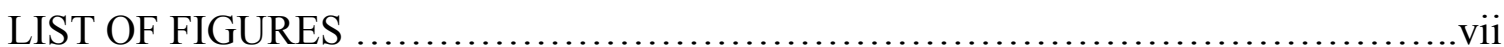

Chapter

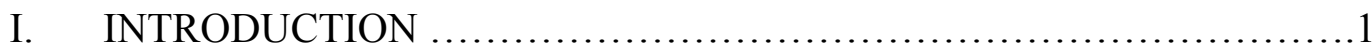

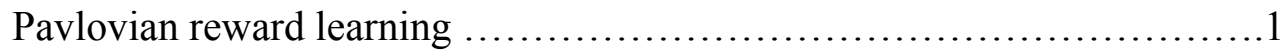

Role of the nucleus accumbens in Pavlovian reward learning ................

II. METHODS …..........................................................

Animals .................................................................

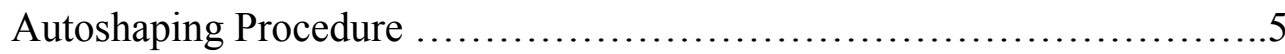

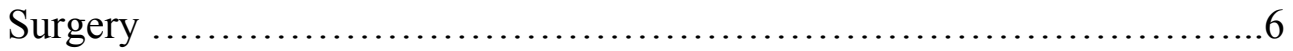

Electrophysiological recordings .....................................

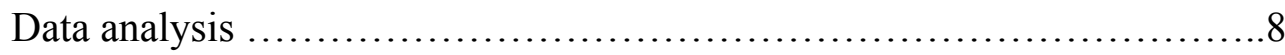

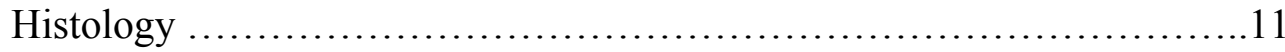

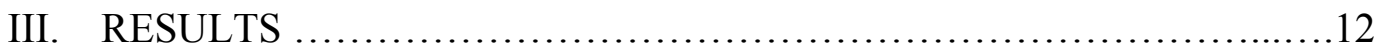

Pavlovian approach behavior ....................................... 12

NAc neurons selectively encode aspects of the autoshaping paradigm................................................

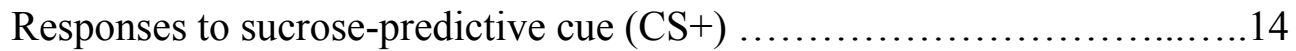

Reponses to non-predictive cue (CS-) ............................... 16

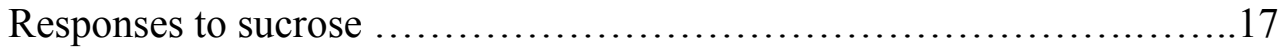


Histology

IV. DISCUSSION ................................................... 19

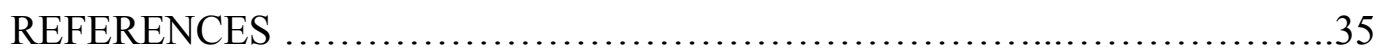




\section{LIST OF FIGURES}

Figure

1. Behavioral performance during autoshaping paradigm...................27

2. Characteristic increase in firing rate of NAc neuron within seconds of CS+ but not CS- presentation..............................28

3. Average activity of CS+ excitatory NAc neurons........................29

4. Characteristic decrease in firing rate of NAc neuron during $\mathrm{CS}+$ but not CS- presentation.................................... 30

5. Average activity of CS+ inhibitory NAc neurons....................... 31

6. Differential responsiveness of NAc neurons during presentation of sucrose predictive versus non-predictive cues.........................32

7. A minority of NAc neurons exhibited phasic responses to

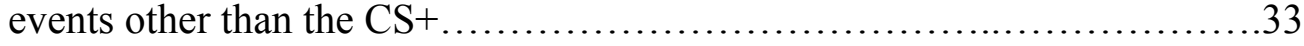

8. Anatomical distribution of electrode placements and cell response types. 


\section{ABBREVIATIONS}

$\begin{array}{ll}\text { ACC } & \text { Anterior cingulate cortex } \\ \text { CeN } & \text { Central nucleus of the amygdala } \\ \text { CR } & \text { Conditioned response } \\ \text { CS } & \text { Conditioned stimulus } \\ \text { DSP } & \text { Digital signal processor } \\ \text { NAc } & \text { Nucleus accumbens } \\ \text { PCA } & \text { Principal components analysis } \\ \text { PEH } & \text { Peri-event histogram } \\ \text { S:B } & \text { Signal-to-baseline } \\ \text { UR } & \text { Unconditioned response } \\ \text { US } & \text { Unconditioned stimulus } \\ \text { VP } & \text { Ventral pallidum } \\ \text { VTA } & \text { Ventral tegmental area }\end{array}$




\section{CHAPTER 1}

\section{INTRODUCTION}

Species survival and propagation requires that individual organisms learn about their surroundings and continually adjust behavior accordingly. One elementary yet biologically critical form of learning involves the connection of positive outcomes with predictive cues. This ability enables organisms to track, locate, and secure food and necessary materials in demanding environments, revealing obvious survival value. Moreover, such learning is often the background for both normal and maladaptive human behaviors. Thus, understanding reward-related learning could shed light on a variety of human activities, including drug taking, food seeking, social attachment, and sexual behavior.

\section{Pavlovian reward learning}

Historically, reward-related learning has been divided into stimulus-outcome (classical or Pavlovian) and action-outcome (operant or instrumental) branches. In the context of Pavlovian learning, biologically relevant outcomes such as food, water, and sexual stimuli are labeled unconditioned stimuli (US) because they are able to evoke innate or unconditioned responses (UR) such as salivation, approach, and consumption (Pavlov, 1927). Pavlovian conditioning procedures involve the pairing of a neutral sensory stimulus, termed the conditioned stimulus (CS) with a US in a temporally contingent manner. Learning occurs as the previously neutral stimulus obtains predictive value for the coming reward based on repeated pairings of the CS and US. Eventually, this novel cue is able to evoke a response 
that is often topographically similar to that produced by the US itself. The learned response that the CS elicits is called the conditioned response (CR).

The existence of a Pavlovian association is typically inferred from the presence or absence of a CR. Therefore, complete understanding of the neurobiological basis of Pavlovian learning requires not only advanced cellular and pharmacological technologies, but also reliable behavioral techniques that can measure the acquisition and maintenance of an association. For example, stimulus-reward learning in animals is often quantified using an "autoshaping" or "sign-tracking" design, in which a CS predicts the availability of a natural reward such as food (US). Initially, food delivery produces orienting and approach responses that are followed by consumption. With repeated CS-US pairings, the CS itself begins to elicit highly selective approach responses even though reward delivery is independent of any specific behavior (Bussey et al., 1997; Robbins and Everitt, 2002). After extended conditioning, approach responses are observed nearly every time the reward-predictive CS is presented to an animal, indicating a strong association between this cue and the future reward. Interestingly, conditioned approach behaviors have been observed in a variety of species, including rats, monkeys, pigeons, and humans (Brown and Jenkins, 1968; Sidman and Fletcher, 1968; Wilcove and Miller, 1974; Bussey et al., 1997), and track diverse rewards such as heat, food, water, intracranial stimulation, intravenous cocaine, and copulation (Peterson et al., 1972; Jenkins and Moore, 1973; Wasserman, 1973; Burns and Domjan, 1996, 2001; Uslaner et al., 2006). Thus, although directed approach behaviors are unlike traditional Pavlovian visceral or glandular responses, they provide a convenient measure of associative reward learning that is highly similar across species. In addition, approach behaviors may be linked to impulsive choice and could provide an interesting 
analogue to compulsive behaviors that develop following repeated drug use (Tomie et al., 1998, 2000).

From an ecological standpoint, reward-related Pavlovian learning may provide several adaptive advantages for an organism in a rapidly changing environment. Successful identification and consumption of unconditioned stimuli such as food involves physical contact that engages proximal receptors of taste, olfaction, and somatosensation. However, because these sensory modalities are not equipped to identify stimuli in a larger environmental field, they may not make up a complete set of tools for efficient foraging behavior. Through Pavlovian learning, visual and auditory information can be incorporated in the foraging experience and utilized to detect and predict available rewards.

\section{Role of the nucleus accumbens in Pavlovian reward learning}

The ability to form and use Pavlovian associations requires the existence and cooperation of brain circuits equipped to integrate sensory and motivational information and alter motor output. The nucleus accumbens (NAc) has received much attention in this respect. It receives convergent glutamatergic input from the prefrontal cortex, hippocampus, and basolateral amygdala, as well as a dopaminergic projection from the ventral tegmental area (VTA). The NAc also projects to motor areas such as the ventral pallidum, making it an ideal location for detailed reward information to be turned into motivated action(Mogenson et al., 1980). Indeed, several lines of research converge in suggesting that the NAc mediates goal-directed behaviors for both drug and natural (e.g., water, sucrose, \& food) rewards (Carelli and Deadwyler, 1994; Wise, 1998; Kelley, 1999; Carelli et al., 2000; Robbins and Everitt, 2002; Di Chiara et al., 2004; Roitman et al., 2004). Moreover, conditioned cues associated with primary reinforcement can evoke patterned responses among NAc neurons 
and elicit dopamine release in this structure (Carelli, 2000; Phillips et al., 2003; Nicola et al., 2004b; Roitman et al., 2005).

The NAc (especially the core subregion) also plays an important role in the development and expression of Pavlovian autoshaping behaviors. Cardinal et al. (Cardinal et al., 2002) demonstrated that excitotoxic lesions of the NAc core impaired the ability of rats to discriminate between a CS+ predictive of reward and a CS- with no predictive value. Furthermore, depletion of dopamine in the NAc resulted in similar deficits in the acquisition and expression of approach behaviors (Parkinson et al., 2002). These results echoed an earlier finding that dopamine antagonists infused into the NAc core impaired approach behavior in ways dissociable from glutamate antagonists (Di Ciano et al., 2001).

Although previous studies identified important roles for specific NAc subnuclei and neurotransmitter systems in mediating the Pavlovian approach response, the firing patterns of NAc cells during this process remain poorly understood. Here, we tested the hypothesis that individual NAc neurons encode both the predictive value of a stimulus and Pavlovian approach actions elicited by conditioned stimuli. In vivo electrophysiological methods were employed to characterize the activity of single NAc neurons during an autoshaping paradigm, where cues either predicted or did not predict sucrose delivery. Thus, the present study assessed the responsiveness of NAc neurons relative to a fundamental aspect of learning (prediction of reward), but also examined the relationship between learned cue-reward associations and biologically significant approach responses. 


\section{CHAPTER 2}

METHODS

\section{Animals}

Male, Sprague Dawley rats (n=9, Harlan Sprague Dawley, Indianapolis, IN) aged 90$120 \mathrm{~d}$ and weighing 260-330 gm were used as subjects and individually housed with a 12:12 light:dark cycle. All experiments were conducted between 9:00 am and 1:00 pm. Bodyweights were maintained at no less than $85 \%$ of pre-experimental levels by food restriction (10-15 gm of Purina laboratory chow each day, in addition to approximately $1 \mathrm{gm}$ of sucrose consumed during daily sessions). This regimen was in place for the duration of behavioral testing, except during the post-operative recovery period when food was given ad libitum. All procedures were approved by the University of North Carolina Institutional Animal Care and Use Committee.

\section{Autoshaping Procedure}

Experimental sessions occurred in $43 \times 43 \times 53 \mathrm{~cm}$ Plexiglas chambers $(\mathrm{Med}$ Associates, St. Albans, VT) housed within sound-attenuating boxes (Fibrocrete, Crandall, GA). Two symmetrically located retractable levers (Colburn Instruments, Allentown, PA) were placed $17 \mathrm{~cm}$ apart on one wall of the chamber. Cue lights were positioned above each lever, but were not active in this experiment. A food receptacle was centered between the levers, $2.5 \mathrm{~cm}$ from the floor. A house light was centrally located on the wall opposite the food receptacle and levers, $2 \mathrm{~cm}$ from the ceiling. 
A session began by placement of an animal into the chamber with the house light illuminated and white noise present. Daily $1 \mathrm{~h}$ sessions consisted of 50 experimental trials. On 25 trials, one retractable lever (the $\mathrm{CS}+$ ) was inserted into the chamber for $10 \mathrm{~s}$ and then retracted, immediately followed by delivery of a $45 \mathrm{mg}$ sucrose pellet (Sucrose Reward Formula F; Noyes, Lancaster, NH) into the food receptacle. On the other 25 trials, a separate lever (the CS-) was inserted into the chamber for $10 \mathrm{~s}$ and then retracted. Importantly, the retraction of the CS- lever was never followed by the unconditioned stimulus (UCS, sucrose). Thus, the CS+ was a positive predictor of sucrose, whereas the CS- was not. Trials were initiated on a variable schedule every 45 to $75 \mathrm{~s}$; the average inter-trial interval was $60 \mathrm{~s}$. Trial type (i.e., CS+ or CS-) was chosen semi-randomly, with no more than two trials of either type occurring in sequence. Additionally, the CS+ lever was counterbalanced left-right across animals and across experimental chambers. Contact with each CS, registered as a lever press, was recorded during every trial. However, lever pressing had no programmed consequences, as sucrose delivery was not dependent upon contact with the CS+. As in previous studies, repeated contact with either cue was interpreted as approach behavior (Di Ciano et al., 2001). After 10 training sessions, all rats exhibited approach responses on more than $80 \%$ of CS + trials, and were surgically prepared for electrophysiological recording.

\section{Surgery}

Animals were anesthetized with ketamine hydrochloride $(100 \mathrm{mg} / \mathrm{kg})$ and xylazine hydrochloride $(20 \mathrm{mg} / \mathrm{kg})$ and microelectrode arrays were implanted with the NAc, using established procedures (Carelli et al., 2000). Electrodes were custom-designed and purchased from a commercial source (NB Labs, Dennison, TX). Each array consisted of eight microwires $(50 \mu \mathrm{m}$ diameter) arranged in a $2 \times 4$ bundle that measured $\sim 1.5 \mathrm{~mm}$ 
anteroposterior and $\sim .75 \mathrm{~mm}$ mediolateral. Arrays were targeted for permanent, bilateral placement in the core and shell subregions of the NAc (AP, $+1.3-1.7 \mathrm{~mm}$; ML, \pm 0.8 or 1.3 $\mathrm{mm}$; DV, $-6.2 \mathrm{~mm}$; all relative to bregma on a level skull, (Paxinos and Watson, 2005)). Ground wires for each array were coiled around skull screws and placed $3-4 \mathrm{~mm}$ into the ipsilateral side of the brain, $\sim 5 \mathrm{~mm}$ caudal to bregma. After implantation, both arrays were secured on the skull using surgical screws and dental cement. All animals were allowed at least 6 post-operative recovery days before being reintroduced to the autoshaping paradigm. Thereafter, animals underwent a final autoshaping training session to ensure stable approach responding before the commencement of electrophysiological recordings during the final test day.

\section{Electrophysiological Recordings}

Electrophysiological procedures have been described in detail previously (Carelli et al., 2000; Carelli, 2002a; Hollander and Carelli, 2005). Before the start of the recording session, the subject was connected to a flexible recording cable attached to a commutator (Med Associates Inc., St. Albans,VT) that allowed virtually unrestrained movement within the chamber. The headstage of each recording cable contained 16 miniature unity-gain field effect transistors. NAc activity was recorded differentially between each active and the inactive (reference) electrode from the permanently implanted microwires. The inactive electrode was examined before the start of the session to verify the absence of neuronal spike activity and served as the differential electrode for other electrodes with cell activity. Online isolation and discrimination of neuronal activity was accomplished using a neurophysiological system commercially available (multichannel acquisition processor, MAP System, Plexon, Inc., Dallas, TX). Multiple window-discrimination modules and high-speed 
analog-to-digital (A/D) signal processing in conjunction with computer software enabled isolation of neuronal signals based on waveform analysis. The neurophysiological system incorporated an array of digital signal processors (DSPs) for continuous spike recognition. The DSPs provided a continuous parallel digital output of neuronal spike events to a Pentium computer. Another computer controlled behavioral events of the experiment (Med Associates Inc., St. Albans,VT) and sent digital outputs corresponding to each event to the MAP box to be time stamped along with the neural data. The neurophysiological system has the capability of recording up to four neurons per microwire using real-time discrimination of neuronal action potentials. However, in the present study 1-2 neurons were typically recorded per active microwire (Chang et al., 1994; Nicolelis et al., 1997; Roitman et al., 2005). Principle component analysis (PCA) of continuously recorded waveforms was performed prior to each session and aided in the separation of multiple neuronal signals from the same electrode. This sophisticated analysis generates a projection of waveform clusters in a three-dimensional space, enabling manual selection of individual waveforms. Before the session, an individual template made up of many "sampled" waveforms was created for each cell isolated using PCA. During the behavioral session, waveforms that "matched" this template were collected as the same neuron. Cell recognition and sorting was finalized after the experiment using the Offline Sorter program (Plexon, Inc., Dallas, TX), when neuronal data were further assessed based on PCA of the waveforms, cell firing characteristics, and interspike intervals.

\section{Data Analysis}

Pavlovian approach responses directed at conditioned stimuli were recorded as lever presses. These data are presented here as the probability of approach for each CS, or the number of trials in which the animal made at least one press on that lever divided by 25 (the 
total number of trials). The differential acquisition of stimulus-selective conditioned appetitive responses was evaluated using a within-subjects cue (2 levels, CS+ and CS- $) \mathrm{x}$ session (12 levels) repeated measures ANOVA (Statistica, StatSoft, Tulsa, OK). NewmanKeuls post-hoc tests were used to elucidate time-specific differences between the cues (CS+ and CS-). Further analyses compared cue-specific contact (mean lever presses during each second of cue presentations) during the test session using a within-subjects cue (2 levels) $\mathrm{x}$ time (10 levels), repeated measures ANOVA. Statistical significance was assessed using an alpha level $\leq 0.05$.

Neuronal firing patterns in the NAc were characterized using raster displays and perievent histograms (PEHs) constructed with commercially available software (NeuroExplorer, Plexon, Inc.). These displayed the activity of each cell during three time epochs: (1) a "baseline" (-10 to $0 \mathrm{~s})$ period prior to CS presentation, (2) the $10 \mathrm{~s}$ cue presentation ( 0 to $10 \mathrm{~s}$ ), and (3) the $10 \mathrm{~s}$ following the CS presentation (10 to $20 \mathrm{~s})$. The result was a histogram that represented cell firing throughout a $30 \mathrm{~s}$ window surrounding $\mathrm{CS}+$ and CS- presentations and sucrose delivery (CS+ only). Consistent with other reports from this laboratory (e.g., (Carelli et al., 2000; Roitman et al., 2005), NAc cells were described as "phasically active" during a given epoch if rates of cell firing increased or decreased by $40 \%$ from baseline rates. Here, cells were classified as having either an "excitatory" or "inhibitory" response to the CS+ or CS- if they exhibited a $40 \%$ rise or fall in activity during any of the first three $1 \mathrm{~s}$ time bins of the CS presentations. In cases where a cell showed both an excitation and inhibition during the initial three seconds of CS onset, the first response was used for classification. Cellular responses to the UCS were similarly assessed during the $5 \mathrm{~s}$ period that followed $\mathrm{CS}+$ retraction/sucrose delivery. Cells that 
exhibited no phasic response to the CS+ were classified as CS- specific (displaying a change in activity in the first $3 \mathrm{~s}$ of the CS- presentation only), sucrose specific (displaying a change in firing rate during the $5 \mathrm{~s}$ following the sucrose delivery, but no response to either cue), or nonphasic (no change in firing rate relative to any experimental event).

The primary goal of this study was to compare cellular responsiveness to cues that did and did not elicit approach responses. Therefore, neuronal data for the excitatory and inhibitory subpopulations of CS+ responsive cells were separately averaged. Then, the mean firing rate for these populations during the CS- presentation was plotted, allowing for a direct comparison between the changes in neural activity evoked by these cues. The effect of a cue's predictive value (and ability to evoke approach responses) on neuronal firing rates was assessed independently for CS+ excitatory and inhibitory cell populations using repeated measures cue (2 levels) x time (11 levels, including baseline) ANOVAs that compared mean baseline firing rates to mean activity during each one-second bin of the cue periods. Newman-Keuls post-hoc tests of the interaction terms were used to determine the time bins at which firing rate differed significantly from baseline or at which a cue difference existed. Signal-to-baseline (S:B) ratios for CS+ excitatory and CS+ inhibitory populations were computed by dividing the "signal" (firing rate for an individual cell during a single second of the cue period), by the baseline (averaged activity for that cell during the $10 \mathrm{~s}$ prior to cue presentation). This analysis controlled for the heterogeneity in baseline firing rates among cells, providing a more conclusive and substantive examination of cue-induced changes in neuronal activity. 


\section{Histology}

Upon completion of the experiment, rats were deeply anesthetized with a ketamine and xylazine mixture (100 mg/kg and $20 \mathrm{mg} / \mathrm{kg}$, respectively). In order to mark the placement of electrode tips, a $15 \mu \mathrm{A}$ current was passed through each microwire electrode for 5 seconds. Transcardial perfusions were then performed using physiological saline and 10\% formalin, and brains were removed. After post-fixing and freezing, $50 \mu \mathrm{m}$ coronal brain sections were mounted and stained with thionin and potassium ferricyanide to reveal a blue reaction product corresponding with the location of an electrode tip. The specific position of individual electrodes was assessed by visual examination of successive coronal sections. Placement of an electrode tip within the NAc core or shell was determined by examining the relative position of observable reaction product to visual landmarks (including the anterior commissure and the lateral ventricles) and anatomical organization of the NAc represented in a stereotaxic atlas (Paxinos and Watson, 2005). Statistically significant differences in the distribution of excitatory and inhibitory cells in the core and shell subregions were assessed by performing a Chi-square test on the frequency of observed cell types. 


\title{
CHAPTER 3
}

\author{
RESULTS
}

\section{Pavlovian Approach Behavior}

Animals rapidly acquired approach behaviors directed at reward-predictive stimuli. Fig. 1A displays the mean probability of approach for all rats across sessions for each cue. On the initial day of testing, naïve rats rarely approached either cue. However, as the number of CS-UCS pairings increased, the probability of approach behaviors directed at the CS + also increased. In contrast, approaches directed at the CS- did not change. By the final test session, approach probability was stable (mean CS+ approach probability, $0.97 \pm 0.02$; mean CS- approach probability, $0.08 \pm 0.05)$. A repeated measures ANOVA revealed a main effect of cue $\left(\mathrm{F}_{(1,8)}=151.14 ; p<0.01\right)$ and a main effect of session $\left(\mathrm{F}_{(11,88)}=14.23 ; p<0.01\right)$ on approach probability. Furthermore, a cue $\mathrm{x}$ session interaction was present $\left(\mathrm{F}_{(11,88)}=28.81 ; p\right.$ $<0.01$ ), demonstrating that the variance in approach responding was session-specific. Posthoc comparisons revealed that rats approached the CS+ more than the CS- at all time points after the third session (all p's $<0.05$ ). The probability of approach towards the CS- never increased from levels achieved in the initial session ( $p>0.05$ for all post-hoc comparisons). The approach response towards the CS+ typically occurred within seconds of its onset. Figure 1B displays an average histogram of the latency to approach the lever (measured as the first press following CS+ extension).

In addition to discriminated approach behavior, rats also exhibited more contact with the $\mathrm{CS}+$, as measured by the number of lever presses during cue periods. This contact 
typically took the form of biting, grasping, and pawing at the lever. Fig. 1C shows the mean number of lever presses for all rats during each second of the CS+ and CS- presentations on the test day. A repeated measures ANOVA revealed a significant effect of cue on lever contact $\left(\mathrm{F}_{(1,8)}=98.09 ; p<0.01\right)$, but no significant effect of time and no interaction between cue and time. The CS+ engendered significantly more lever presses than the CS- during each time bin. Moreover, lever contact was relatively stable during the CS+ presentation; the rate of lever presses was not significantly increased or decreased across the $10 \mathrm{~s}$ presentation.

\section{NAc neurons selectively encode aspects of the autoshaping paradigm}

Our primary goal was to characterize the activity of NAc neurons during the presentation of cues that either predicted or did not predict sucrose. Thus, although we observed phasic cellular responses to the CS+, CS-, and the UCS, we first sought to characterize response types based on firing rates relative to the CS+. Of 76 NAc neurons isolated and recorded during the autoshaping task, 57 (75\%) showed a phasic change (increase or decrease) in firing rate within seconds of the CS+ onset. Of these neurons, 27 cells responded with excitations in firing rate, while 30 responded with inhibitions. Nearly half of all CS+ responsive cells (28 out of 57, or 49\%) exhibited opposite or nonphasic responses during the CS- period. Only 19 neurons did not show a phasic change in firing pattern relative to the $\mathrm{CS}+$, but the majority (15/19 cells) were responsive during other aspects of the task. Specifically, some neurons $(n=4)$ responded to the CS- alone while another population of cells $(n=11)$ responded to sucrose delivery alone. Finally, the remaining 4 cells exhibited no phasic patterned activity during the autoshaping task, classified as nonphasic. A more detailed description of each type of neuronal pattern during the autoshaping procedure is presented below. 


\section{Responses to sucrose-predictive cue (CS+)}

The rasters/peri-event histograms (PEHs) in Figure 2 show the activity of a single NAc neuron that was excited during CS+ presentation, across baseline, cue, and post-cue epochs. This neuron exhibited a baseline firing rate of $0.28 \mathrm{~Hz}$, but peaked to $10.72 \mathrm{~Hz}$ during the first second of the CS+ presentation (top panel). Firing rate then declined monotonically during the remainder of the $\mathrm{CS}+$ period, spiked again upon lever retraction and sucrose delivery, and remained elevated during sucrose consumption. In contrast, during the CS- presentation (bottom panel) the same cell exhibited no substantial changes in activity compared to baseline firing.

The mean activity of all CS + excitatory cells $(n=27$; mean baseline firing rate \pm $\mathrm{SEM}=2.62 \pm 0.93)$ is illustrated in the composite PEHs in Figure 3. Interestingly, the majority of CS+ excitatory cells (19 of 27 , or $70 \%$ ) also responded to the CS- with excitations. However, as is evident in Figure 3, the magnitude of the composite response for the CS- was relatively blunted as compared to the CS+ response. A repeated measures ANOVA on mean cell firing during these periods revealed a main effect of time $\left(\mathrm{F}_{(10,260)}=\right.$ $4.26 ; p<0.01)$, as well as a significant interaction between cue and time $\left(\mathrm{F}_{(10,260)}=1.87 ; p<\right.$ $0.05)$. There was no main effect of cue $\left(\mathrm{F}_{(1,26)}=2.40 ; p=0.13\right)$. Newman-Keul post hoc comparisons revealed that firing rate was significantly increased over baseline rates during each 1-s time bin of the CS+ period (all p's $<0.05$ ). In contrast, firing rate was only significantly increased during the first second of the CS- presentation. Additionally, firing rate was significantly higher in the first, second, third, fifth, and sixth seconds of the CS+ period than during the same seconds of the CS- period. Thus, this population of neurons responded to the sucrose predictive cue with robust excitations that were strongest during the 
first few seconds of the cue presentation. The same cells responded to the non-predictive cue with transient, less substantial excitations.

Figure 4 shows an example of a representative CS+ neuron that displayed an inhibition in cell firing during the CS+ period. This neuron had a baseline firing rate of 3.8 $\mathrm{Hz}$, but fired at $1.44 \mathrm{~Hz}$ or lower during each second of the CS+ presentation. Cell activity returned to baseline levels following cue retraction, and then increased steadily until roughly 8 s seconds after sucrose delivery. Conversely, no changes were observed during the CSpresentation. The inhibitory response of this neuron was therefore selective for the predictive cue.

Composite PEHs showing the average activity of all CS+ inhibitory neurons $(\mathrm{n}=30$; mean baseline firing rate $\pm \mathrm{SEM}=1.909 \pm 0.51)$ relative to $\mathrm{CS}+$ and CS- presentations are displayed in Figure 5. Mean firing rate of CS+ inhibitory cells was significantly affected by cue $\left(\mathrm{F}_{(1,26)}=23.09 ; p<0.01\right)$ and time $\left(\mathrm{F}_{(10,260)}=3.59 ; p<0.01\right)$ as assessed by a repeated measures ANOVA. In addition to these main effects, there was a significant interaction between cue and time $\left(\mathrm{F}_{(10,260)}=6.82 ; p<0.01\right)$. Post hoc comparisons revealed that mean firing rate was significantly decreased from baseline at all time points during the CS+ presentation (all $p$ 's $<0.05$ ). Furthermore, neuronal activity during the CS+ period was lower than activity during the CS- period for every 1-s time bin ( $p$ 's $<0.05$ for each second). On average, these cells exhibited no patterned phasic response to the cue that did not precede sucrose.

Signal-to-baseline (S:B) ratios were calculated for CS+ excitatory and CS+ inhibitory neurons to control for differences in baseline firing rates across cells, and provide more detailed information regarding second-to-second changes in cell firing during each cue 
presentation. S:B ratios across time for $\mathrm{CS}+$ excitatory and $\mathrm{CS}+$ inhibitory neurons are shown in Figures 6A and 6B, respectively. The mean S:B ratio of CS+ excitatory neurons (n $=27$ ) increased to over 3 during the first second of the CS+, signifying a $200 \%$ increase in cell firing relative to baseline. In contrast, the same cells exhibited more modest increases $(\sim 70 \%)$ during the first second of the CS- period. The excitatory action of these cells was evident for the duration of the CS+ period, but returned to baseline levels for the majority of the CS- period. The mean S:B ratio of CS+ inhibitory cells was even more striking (Figure 6B). At each time point during the presentation of the sucrose predictive cue, the $\mathrm{S}: \mathrm{B}$ ratio was close to 0.5 , meaning that the firing rate of these cells was reduced by half. Conversely, the mean S:B ratio of the same cells during the CS- presentation was never below 1, indicating that activity of this subpopulation did not change relative to the non-predictive cue.

\section{Reponses to non-predictive cue (CS-)}

Fifty-five percent of all NAc neurons were phasically active during the CS- period, with 29 cells exhibiting an excitatory response and only 13 displaying an inhibitory response. However, of 76 neurons recorded in this study, only $4(5 \%)$ responded to the CS- but not the CS+. Three of these cells exhibited an excitation when the CS- was presented. A representative example of this cell type is displayed in Figure 7A. During the baseline period for the CS+, this cell fired at an average of $2.95 \mathrm{~Hz}$. The activity of this cell did not deviate by more than $40 \%$ from this rate during any $1 \mathrm{~s}$ bin of the sucrose-predictive cue. The baseline rate preceding the CS- period was $2.92 \mathrm{~Hz}$, but increased to $5.0 \mathrm{~Hz}$ during the first second of the CS- presentation, a clear excitatory response. Firing rate returned to baseline levels during the remainder of the CS- presentation, and exhibited another excitation 
(peaking at $6.28 \mathrm{~Hz}$ ) upon lever retraction. As the occurrence of this cell type (CS- specific) was infrequent, composite data are not presented here.

\section{Responses to sucrose}

Sixty-eight NAc units (89\%) exhibited changes in firing rate within $5 \mathrm{~s}$ following sucrose delivery. Eleven (16\%) of these cells were not responsive to either cue, but exhibited phasic changes in cell firing only during sucrose delivery and consumption. Of this group, 9 cells displayed robust excitations in response to sucrose, whereas 2 responded with inhibitions. Figure 7B shows an example of a single representative neuron that displayed an excitatory response during sucrose availability alone. Cell activity was stable during the baseline periods (CS+ baseline, $3.97 \mathrm{~Hz}$; CS- baseline, $3.72 \mathrm{~Hz}$ ) and did not deviate during the presentation of either cue. However, $4 \mathrm{~s}$ after the retraction of the $\mathrm{CS}+$, the firing rate was elevated to $14.4 \mathrm{~Hz}$. There was no excitatory response during the same period following the retraction of the CS-. Indeed, the phasic response of this cell was selective for sucrose, and was not influenced by predictive or non-predictive cues. Again, because this and similar cells accounted for a relatively small percentage of overall patterned responding, composite data are not shown here.

\section{Histology}

A total of 144 microwire electrodes (16 per animal) were implanted in the brains of 9 animals. Forty-nine neurons were recorded from 72 wires histologically verified to be in the NAc core. Likewise, 27 neurons were recorded from 44 wires located in the shell. Thus, not every wire yielded neural data, and in some cases, more than one cell was recorded per wire (i.e., there was not a one-to-one correspondence between each wire and neural data). Additionally, 17 individual neurons were recorded on the remaining 28 electrodes placed 
outside of the NAc. Since those wires were distributed randomly across multiple neural structures, resulting data were excluded from this study. Across all animals, bilateral electrode placements in the NAc ranged from 0.96-2.52 mm anterior to bregma and 0.5-2.5 $\mathrm{mm}$ lateral to the midline. Figure $8 \mathrm{~A}$ shows the distribution of marked electrode tip placements across all animals according to the stereotaxic atlas of Paxinos and Watson (2005). Only electrodes that recorded at least one neuronal waveform are included in this figure.

Figure $8 \mathrm{~B}$ shows the observed frequency of cellular response types across stimuli (as a percentage of total neurons recorded in the core or shell). There was a differential distribution of neurons that exhibited excitations to the CS+ or CS- during the task. Specifically, a significantly greater percentage of neurons in the NAc core displayed excitations to conditioned stimuli $\left(\chi^{2}=6.503, p=0.01\right.$ for $\mathrm{CS}+; \chi^{2}=5.615, p=0.017$ for CS). However, no significant differences were observed between excitatory responses in core and shell neurons following the UCS $(p=0.39)$. Additionally, there were no significant core/shell differences in the proportion of neurons that displayed inhibitory responses to the conditioned cues or the UCS (all $p$ 's $>0.05$ ). It is important to note that there was overlap in populations of neurons that were classified across the dimensions shown in Figure 8B. In other words, the CS+, CS-, and UCS categories constructed in this figure are not mutually exclusive. For example, an individual neuron could be both inhibitory relative to the CS+ presentation and excitatory relative to UCS delivery. 


\section{CHAPTER 4}

\section{DISCUSSION}

The present study offers the first evidence of patterned NAc activity during the execution of simple Pavlovian approach behaviors toward stimuli that predict rewards. Consistent with other reports (Bussey et al., 1997; Di Ciano et al., 2001; Cardinal et al., 2002), rats rapidly acquired approach responses directed almost exclusively at a CS + that predicted sucrose delivery. A series of studies have demonstrated that such repetitive approach behaviors are subserved by key interactions between the NAc and associated nuclei (Parkinson et al., 2000; Di Ciano et al., 2001; Cardinal et al., 2002; Parkinson et al., 2002). The present results confirm those reports and provide insight into cellular mechanisms involved in autoshaping. Specifically, the vast majority of NAc cells recorded here exhibited robust, phasic changes in firing rate within milliseconds of $\mathrm{CS}+$ onset. However, several subpopulations were observed. One subset was characterized by sustained increases in firing rate during $\mathrm{CS}+$ presentation. This population also responded to the seldom-approached CS-, but excitations were significantly smaller in magnitude than those observed for the CS+. Another group of neurons showed significant inhibitions in firing rate for the duration of the $\mathrm{CS}+$ period. The same cells exhibited little or no change in activity during the CS- period, indicating a relative specificity for stimuli that predict sucrose and elicit approach responses. The finding that NAc neurons demonstrate two distinct patterned responses during autoshaping corroborates evidence suggesting that functional ensembles - or coordinated 
neuronal networks - in the NAc act to integrate diverse signals and carry out different tasks during reward-related events (Carelli and Wightman, 2004). Additionally, our observation that the firing patterns reported here were differentially distributed in the NAc core and shell suggests that these subregions play different roles during autoshaping.

A cue predicting a natural appetitive stimulus (sucrose) elicited striking excitations in a considerable percentage (36\%) of NAc neurons (classified as CS+ excitatory cells). Recent investigations have reported similar excitations evoked by cues signaling both drug and food rewards (Nicola et al., 2004b). These excitations may originate from glutamatergic inputs from cortical and limbic structures (Pennartz et al., 1994; Nicola et al., 2000; Nicola et al., 2004b; Wilson and Bowman, 2004). However, temporally similar cue-evoked excitations have also been observed in dopamine neurons in rodent and primate striatum (Schultz et al., 1993; Pan et al., 2005). The degree of these responses vary based on the nature, size, and certainty of the reward being predicted (Hassani et al., 2001; Cromwell and Schultz, 2003; Fiorillo et al., 2003). The dopaminergic innervation from the VTA is required for cue responses in the NAc (Yun et al., 2004). Additionally, NAc dopamine concentration rapidly increases in response to predictive cues (Phillips et al., 2003; Roitman et al., 2004), supporting the hypothesis that NAc dopamine modulates the ability of glutamatergic inputs to drive NAc cell firing (Cepeda and Levine, 1998; Nicola et al., 2000; Wise, 2004; Goto and Grace, 2005). Thus, while cortical areas could excite NAc neurons during autoshaping, dopaminergic signals may gate the nature and function of those excitations.

The magnitude of CS+ excitatory responses identified here may only partially depend on the predictive value of the cue. The non-predictive CS- also elicited significant (but relatively blunted) excitations in the same cells, but did not produce conditioned approach 
responses. Thus, the excitatory signal may not encode conditioned movements per se, but may simply reflect orienting responses directed at dynamic events in a changing environment, or rapid movements in general. While this is certainly a possibility, several studies suggest otherwise. Using detailed videotape analysis, Woodward and colleagues (Chang et al., 1994) compared NAc cell activity relative to lever presses and orienting motor responses in a cocaine-self administration paradigm with similar movements that occurred during the inter-trial interval. Those authors demonstrated that phasic patterns of cell firing in the NAc were specific to goal-directed events. NAc neurons did not exhibit patterned discharges (excitations or inhibitions) during the execution of similar actions that did not produce cocaine. Other investigations have corroborated these findings (Ljungberg et al., 1992; Peoples et al., 1998), suggesting that the firing patterns of NAc neurons are specifically altered by reward-related events, and not movement alone.

It is possible that the excitations observed for the CS- may also be the result of conditioning history. Both NAc and dopamine neurons respond to predictive and nonpredictive stimuli, and this effect had been attributed to stimulus generalization (Mirenowicz and Schultz, 1996; Nicola et al., 2004b). In the present study, the CS+ and CS- were alike in every way except spatial location, leaving open the possibility that generalization occurred. As a predictive cue, the CS+ may produce a response among NAc neurons as its incentive value increases (Berridge and Robinson, 1998). Likewise, other stimuli that share its physical properties may develop their own salience and come to elicit similar cellular responses. The observation that excitatory responses were generally much larger relative to the CS+ onset seems to support the latter explanation. Furthermore, significant differences between CS+ and CS- excitations tended to occur early in the cue period (see Fig. 6), when spatial 
distinction between cues would be necessary to direct an approach response. Another intriguing possibility is that the CS- elicits a conditioned avoidance response in well-trained animals. If so, it seems likely that such a response would also be encoded by the NAc.

Another subset of NAc neurons (39\%) exhibited strong inhibitions in cell firing for the duration of the CS+ (termed CS+ inhibitory cells). The same cells showed no change in activity when the CS- was presented, indicating that NAc inhibitions may be critical to the execution of approach responses. As discussed by Nicola and colleagues (2004b) and supported elsewhere (Kelley, 2004; Roitman et al., 2005), NAc inhibitions may be linked to motor actions leading to or associated with food consumption. Decreases in the firing rate of NAc neurons are tightly correlated with oro-motor behavior directed at sucrose consumption (Roitman et al., 2005), and also during operant responding for sucrose, water, cocaine, and heroin (Carelli et al., 1993; Carelli and Deadwyler, 1994; Chang et al., 1994; Chang et al., 1996; Chang et al., 1997; Ghitza et al., 2004; Nicola et al., 2004b). Here, approach responses usually occurred less than 2s after the CS+ presentation, and animals maintained contact with the CS+ for the remainder of the cue period. The finding that inhibitory responses were timelocked to the initial approach as well as subsequent contact suggests that inhibitory signals may encode appetitive reactions to reward-predictive cues. A major output of the NAc is a GABAergic connection with the ventral pallidum (VP) (Usuda et al., 1998). The inhibition of this projection would result in the disinhibition of VP neurons, which can elicit feeding behavior (Stratford and Kelley, 1999) and increase locomotion (Gong et al., 1997). Thus, the NAc inhibitions observed here may act through the VP to sustain appetitive contact with the $\mathrm{CS}+$. These inhibitions may originate from reciprocal connections between NAc neurons (Nicola et al., 2004b). This hypothesis accounts for the observation that excitatory and 
inhibitory subpopulations tend to be of equal sizes, as reported here. Alternatively, an inhibitory response could arise from the GABAergic projection back from the VP, in which case the inhibition of NAc neurons would reflect (but not mediate) Pavlovian approach behaviors.

The magnitude of cue-related neural responses reported here, coupled with the prevalence of cells exhibiting such changes, provides compelling evidence that the NAc encodes aspects of the autoshaping paradigm. Electrophysiological investigations in the NAc typically report that less than half of recorded neurons exhibit a phasic change in firing rate relative to behavioral or environmental events (Chang et al., 1996; Carelli et al., 2000; Carelli, 2002a; Nicola et al., 2004a). Here, $89 \%$ of NAc neurons exhibited robust changes in activity when either sucrose or a sucrose-predictive cue was presented. Some evidence suggests that NAc neurons can develop responses to an event even when they are not initially activated by that event (Carelli, 2002b; Hollander and Carelli, 2005). Interestingly, responses to cues in a subset of NAc neurons do not appear to be innate (i.e., they are not present in naïve animals), but emerge when cues predict appetitive or aversive events (Setlow et al., 2003; Roitman et al., 2005).

The high percentage of phasically active cells in the present study may indicate that the NAc becomes increasingly engaged after repetition of a behavior or a learned association. One theory holds that predictive stimuli promote a specific behavioral action by competing for motor resources controlled by striatal circuits (Pennartz et al., 1994; Plenz, 2003). The response of NAc neurons to predictive cues may originate from this competition and produce the relatively inflexible approach responses observed here. Indeed, the NAc may add a compulsive element to the stimulus-outcome associations present in this design, allowing 
them to dominate behavioral output. Interestingly, approach responses persist even when they cancel reward delivery (Brown and Jenkins, 1968), supporting the idea that impulsivity and autoshaping may be linked phenomena that are both controlled by the NAc (Tomie et al., 1998; Cardinal et al., 2001; Winstanley et al., 2005).

Several researchers have proposed that conditioned approach responses may be a central component of the drug-addicted state (Newlin, 1992; Tomie et al., 2002; Everitt and Robbins, 2005). However, such assertions are not without controversy. Kearns and Weiss (Kearns and Weiss, 2004) recently employed cocaine as a UCS in an autoshaping paragdigm and found that, unlike sucrose, neither high nor low doses of cocaine are able to promote approach responses to stimuli that predict reward delivery. Additionally, requiring an artificial consummatory response before the cocaine infusion did not increase approach responding. This conclusion seems to suggest that cocaine alone cannot support Pavlovian approach responses. However, it is also possible that differences between cocaine and sucrose delivery, such as the timing of the cocaine infusion, may have contributed to the results. Indeed, a previous investigation demonstrated that an ingested ethanol/saccharine combination can support Pavlovian approach responses to spatial predictors (Krank, 2003). Clearly, future parametric studies will be required to determine precise similarities and/or differences between natural and drug reinforcers with respect to conditioned approach liability.

In addition to describing the phasic activity of NAc neurons during autoshaping, our findings may also highlight potential differences between NAc subregions. Significantly fewer neurons in the NAc shell exhibited excitatory responses to conditioned cues, regardless of whether those cues elicited approach responses. While this discrepancy is based on 
relatively small sample sizes, and should be interpreted carefully, it is perhaps not surprising that we found differences between these two regions. Lesions and pharmacological manipulations in the NAc core disrupt selective approach towards predictive stimuli, indicating that this subregion may help organisms discriminate between biologically relevant and irrelevant cues (Di Ciano et al., 2001; Cardinal et al., 2002). Furthermore, recent electrophysiological studies have also unmasked distinctions between neural responses in the core and shell (Ghitza et al., 2004; Ghitza et al., 2006). However, it should also be noted that there were no differences in the present study between the proportion of core and shell neurons that responded with inhibitions. While the NAc core and shell subregions have some overlapping outputs, they also send separate projections to functionally dissimilar regions. For example, the core sends outputs to the substantia nigra and dorsal globus pallidus, while the shell sends more axons to the VTA (Heimer et al., 1991; Everitt and Wolf, 2002). At this time, the precise downstream significance of NAc excitations and inhibitions with respect to autoshaping are unclear.

The present results provide support for the hypothesis that limbic information concerning predictive stimuli is integrated by the NAc, which promotes the motor behaviors necessary to obtain rewards (Mogenson et al., 1980). A recent review posited that critical interactions between the NAc core, central nucleus of the amygdala $(\mathrm{CeN})$, and anterior cingulate cortex (ACC) underlie the proper acquisition and performance of the Pavlovian approach response (Robbins and Everitt, 2002), as lesions to the CeN or ACC impair the also acquisition of approach responding. Indeed, glutamatergic inputs from the ACC may disambiguate the CS+ and CS- during autoshaping, while the CeN may invigorate approach responding through control of midbrain dopaminergic signals to the NAc (Robbins and 
Everitt, 2002). In the context of drug addiction, conditioned cues may precipitate relapse by promoting impulsive, engrained approach responses via this circuitry (Robbins and Everitt, 2002). Understanding the functional interactions between limbic, cortical, and striatal networks may elucidate the processes by which predictive cues come to exert powerful control over behavioral output. 
Figure 1. Behavioral performance during autoshaping paradigm. A, Acquisition of Pavlovian approach responses. Animals $(n=9)$ approached the predictive conditioned stimulus $(\mathrm{CS}+)$ significantly more than the non-predictive conditioned stimulus (CS-) after session 3 (*p $<$ 0.05 stimulus comparison). After 10 training sessions animals received surgical implantation of microelectrode arrays (indicated by break in graph) followed by one post surgical recovery session (session 11). Electrophysiological data was collected during the test session completed the next day (indicated by "T"). B, Averaged histogram of latency to approach the $\mathrm{CS}+$ on the test day. The majority of approach responses occurred within seconds of the CS+ presentation. C, Lever presses per second on the test day. Animals made more contact with the CS+ than the CS- in every 1s time bin. After the initial approach, contact with the CS+ was maintained for the duration of the cue period.
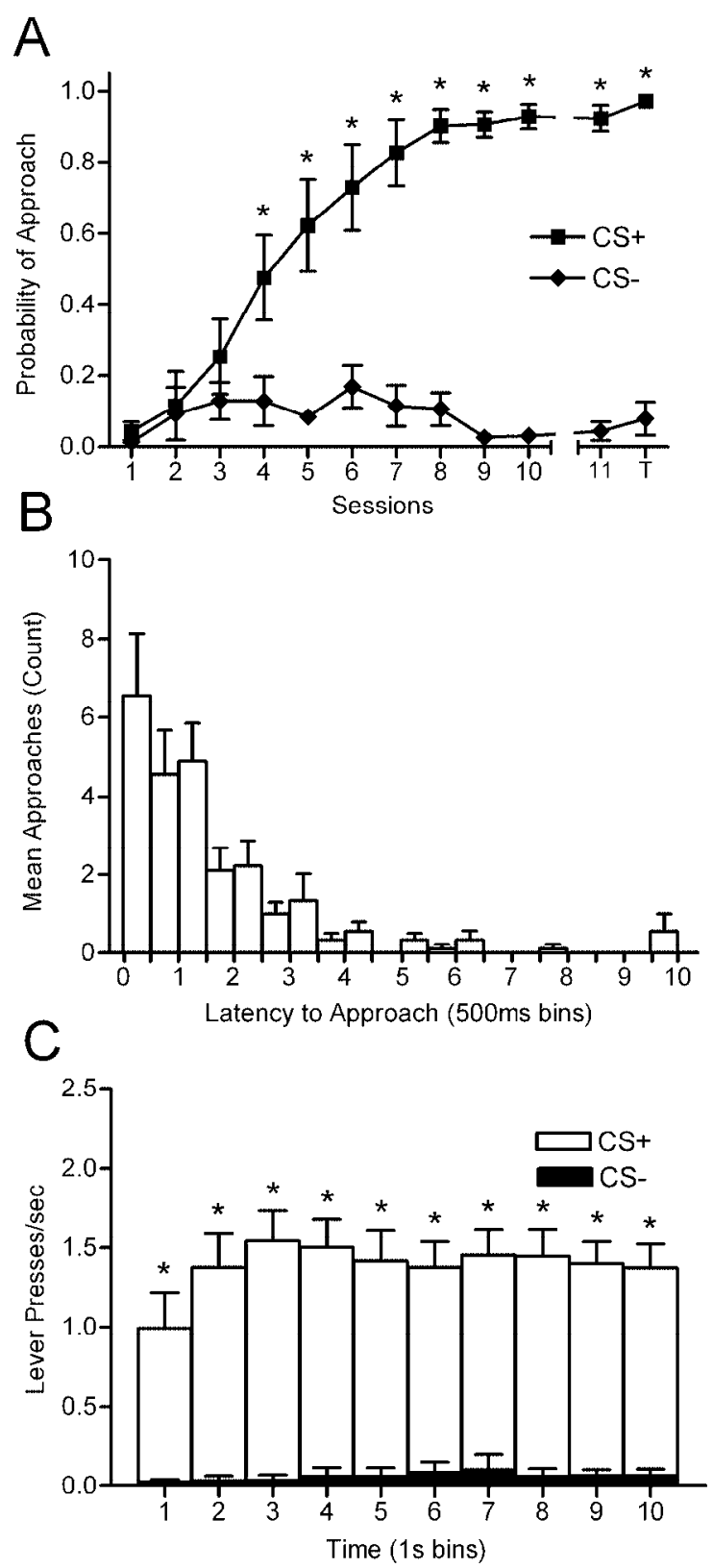
Figure 2. Single nucleus accumbens (NAc) neuron showing a characteristic increase in firing rate within seconds of the CS+ (top panel) but not the CS- (bottom panel) presentation. Top, raster plot and perievent histogram (PEH) in a 30s window relative to CS+ extension (first dashed line) and lever retraction/sucrose delivery (second dashed line). Bottom, raster plot and PEH for the same neuron during a 30s window surrounding the CS- period, after which no sucrose was delivered.

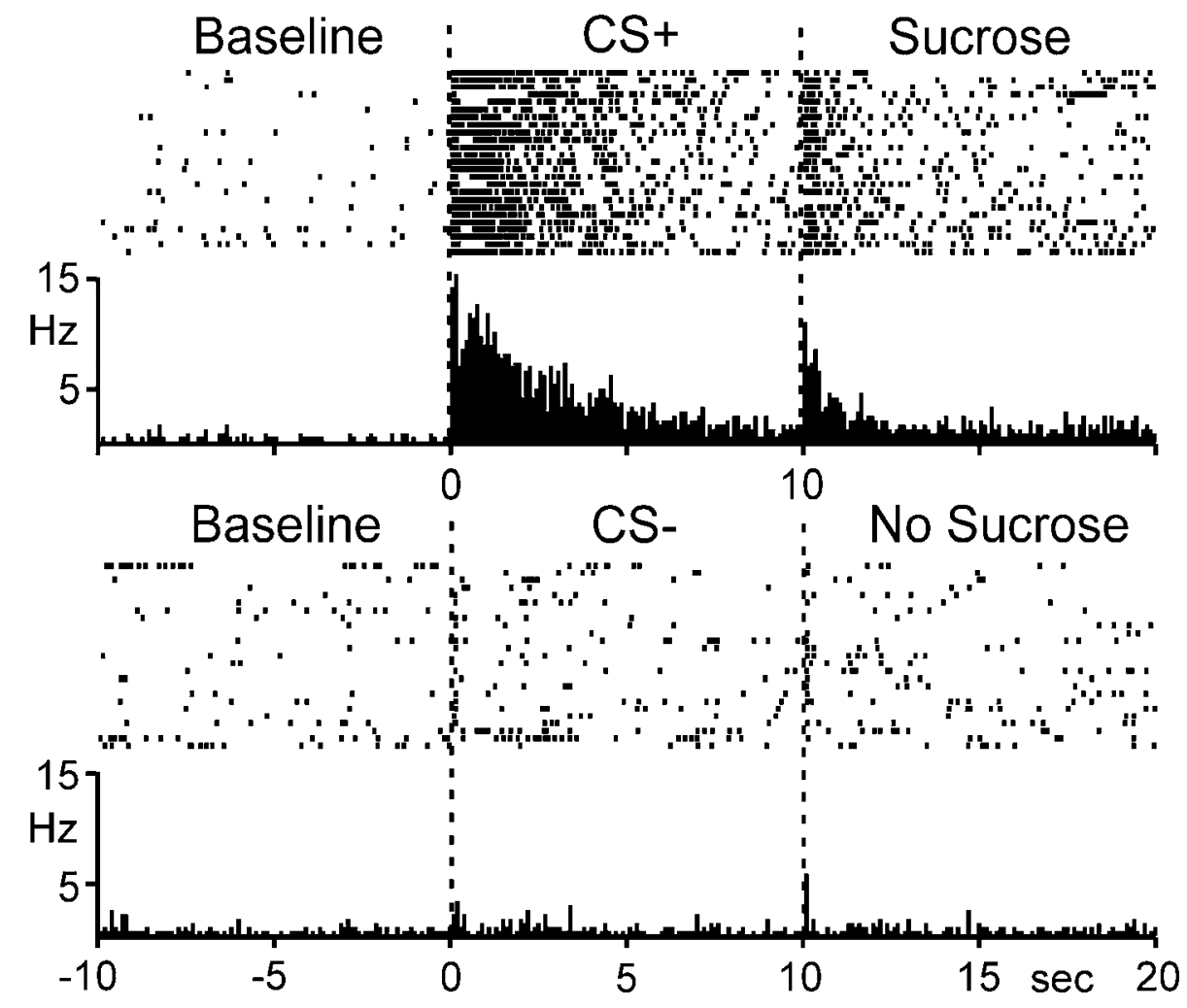


Figure 3. Composite peri-event histograms (PEHs) showing average activity of CS+ excitatory NAc neurons $(n=27)$. A, NAc neurons exhibit excitatory responses to a sucrose predictive cue. Composite PEH of NAc neurons during a 30s window surrounding the CS+ presentation (first dashed line) and lever retraction/sucrose delivery (second dashed line). B, Composite PEH showing the same neurons during the CS- extension and retraction. Excitations were of lesser magnitude and shorter duration.
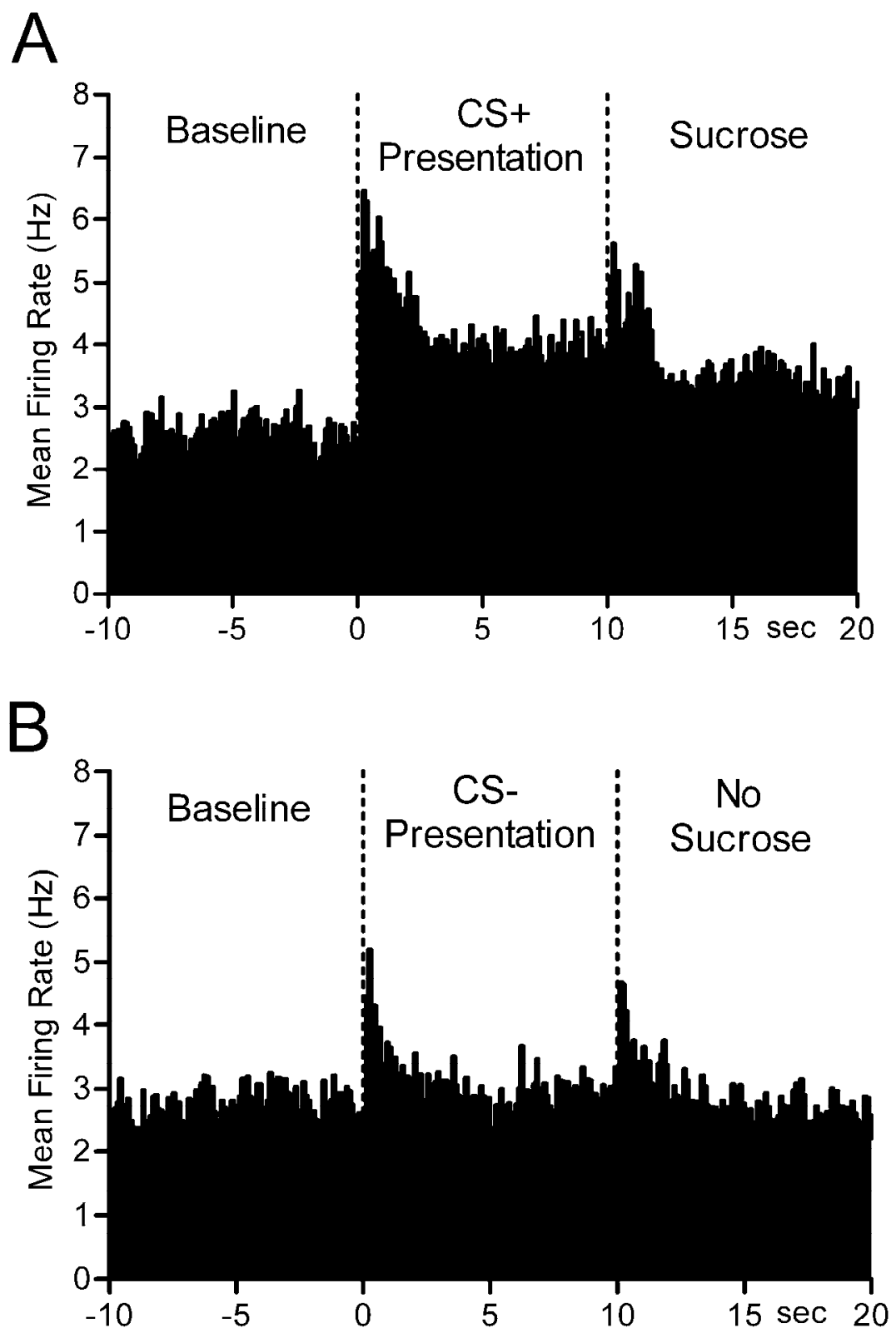
Figure 4. Example NAc neuron showing a decrease in firing rate during the CS+ but not the CS- presentation. Top, raster plot and PEH in a 30s window relative to CS+ extension (first dashed line) and lever retraction/sucrose delivery (second dashed line). Bottom, raster plot and PEH for the same neuron during a 30s window surrounding the CS- period, after which no sucrose was delivered.

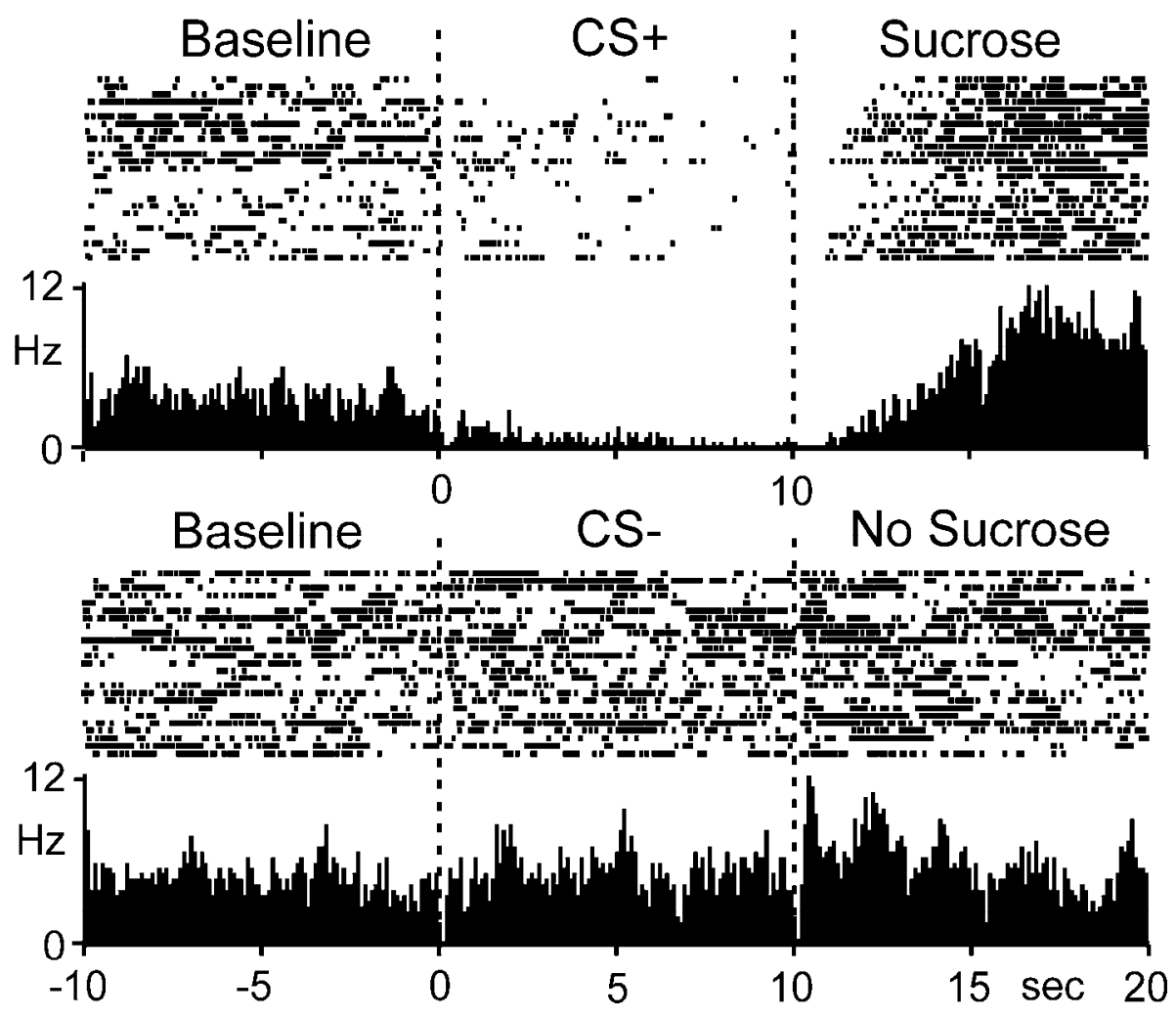


Figure 5. Composite PEH showing average activity of CS + inhibitory NAc neurons $(n=30)$. A, Composite PEH of NAc neurons during a 30s window surrounding the CS+ presentation (first dashed line) and lever retraction/sucrose delivery (second dashed line). NAc neurons exhibit robust inhibitions during the presentation of a sucrose-predictive cue. B, Composite PEH showing no change in cell firing for the same neurons during a 30s window surrounding the CS- presentation.
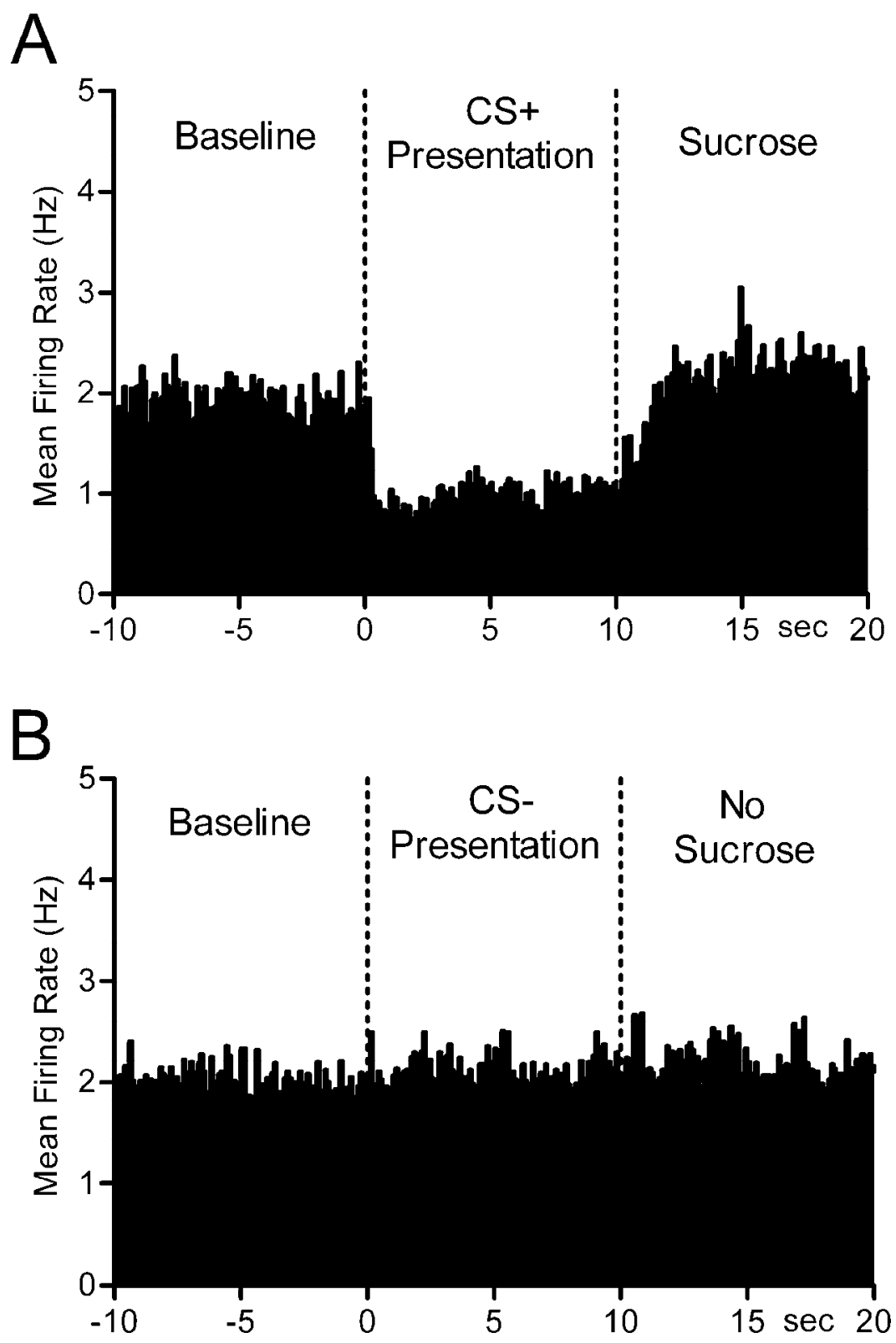
Figure 6. Signal-to-baseline ratios $(\mathrm{S}: \mathrm{B})$ for $\mathrm{CS}+$ excitatory and $\mathrm{CS}+$ inhibitory neurons shows differential responsiveness during sucrose predictive versus non-predictive cues. A, Average S:B ratios for CS+ excitatory cells during each second of the CS+ and CSpresentations (see methods for details). While the CS- elicited significant excitations only in the initial second, the CS+ produced significant increases in firing rate for each time point. B, Average $\mathrm{S}: \mathrm{B}$ ratios for $\mathrm{CS}+$ inhibitory cells during each second of the CS+ and CSpresentations. Mean firing rate during the $\mathrm{CS}+$ period was significantly decreased from baseline rates and was lower than activity during the corresponding time points of the CSperiod. * significant $(p<0.05)$ change in mean firing rate from baseline levels, ** significant $(p<0.05)$ difference in mean firing rate between stimuli for that second and in mean firing rate from baseline levels.

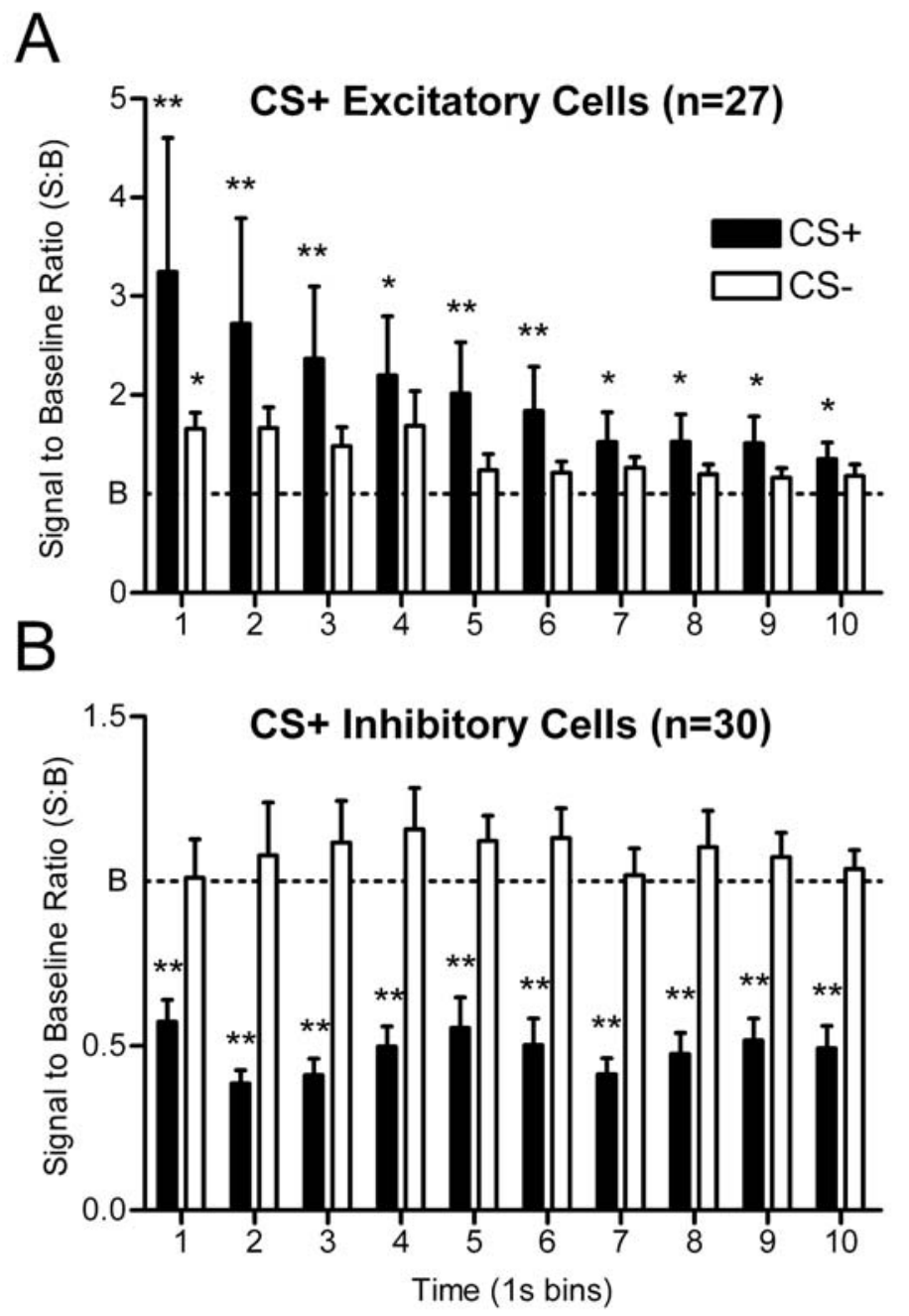


Figure 7. A minority of NAc neurons exhibited phasic responses to events other than the $\mathrm{CS}+$. A, Raster and $\mathrm{PEH}$ for single NAc unit exhibiting a $40 \%$ increase in firing rate when the CS- was presented, but no significant change when the CS+ was presented. Only $5 \%$ of neurons recorded here responded to the CS- but not the CS+. B, Raster and PEH for individual sucrose-responsive NAc cell. This cell showed no changes in activity when either cue was presented, but was specific to the period after sucrose delivery. Only $14 \%$ of cells responded to sucrose alone.

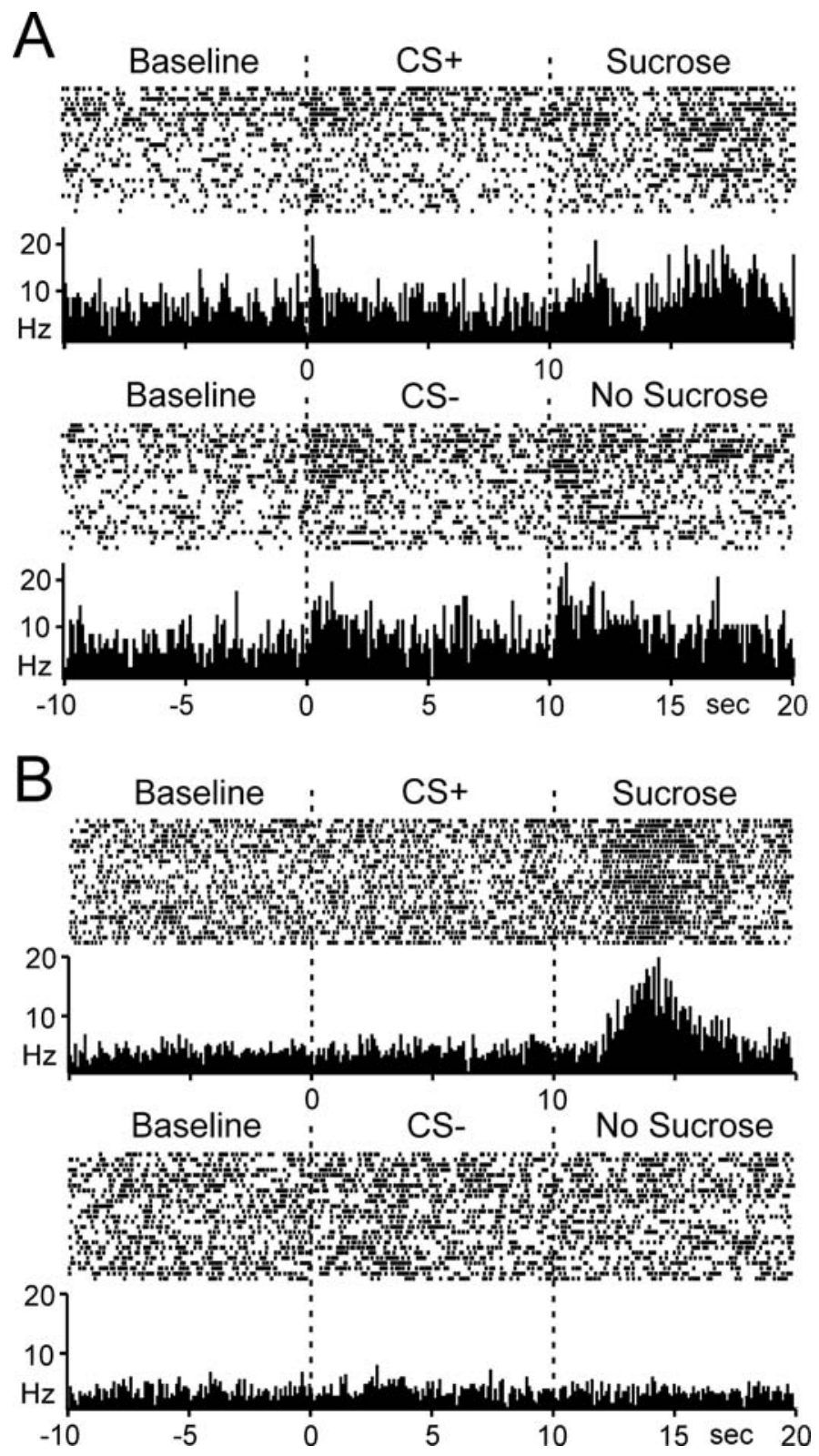


Figure 8. Anatomical distribution of electrode placements and cell response types. A, Coronal diagrams displaying marked electrode tip locations across all 9 animals. Marked locations are limited to electrodes that contributed neuronal data. Filled circles indicate wires located in the NAc core subregion; open circles indicate wires located in the NAc shell. Electrode tip locations were marked by the presence of a blue dot reaction product. Numbers to the right indicate the anteroposterior coordinates (in millimeters) rostral to bregma. Coordinates were taken from the stereotaxic atlas of Paxinos and Watson (2005). B, Percentage of phasic neurons in the core and shell subregions of the NAc, separated by response type and stimulus. Significantly more neurons in the NAc core responded to conditioned stimuli with an excitation $\left({ }^{*} p<0.05\right)$. There were no core/shell differences with respect to UCS excitations or inhibitions relative to any stimulus.
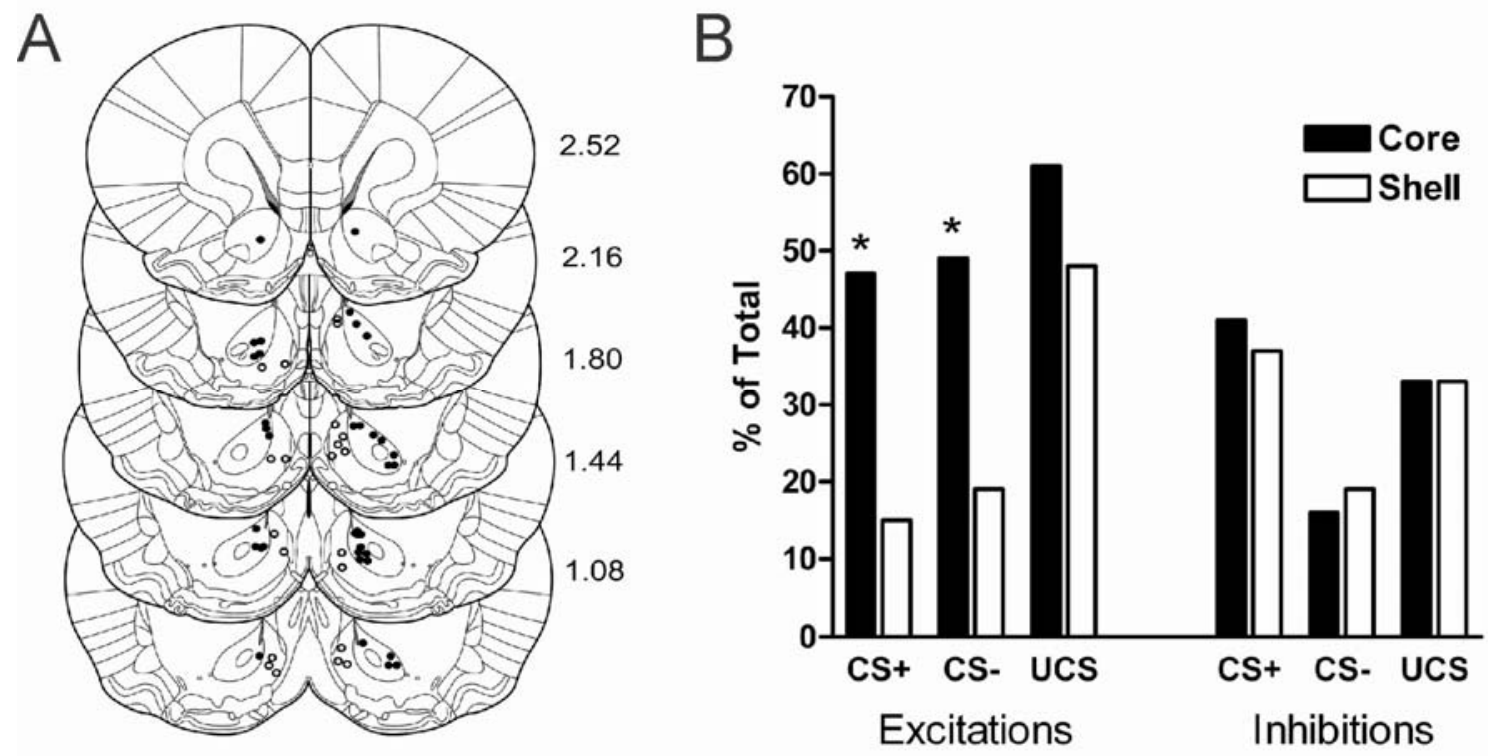


\section{REFERENCES}

Berridge KC, Robinson TE (1998) What is the role of dopamine in reward: hedonic impact, reward learning, or incentive salience? Brain Res Brain Res Rev 28:309-369.

Brown PL, Jenkins HM (1968) Auto-shaping of the pigeon's key peck. J Exp Anal Behav 11:1-8.

Burns M, Domjan M (1996) Sign tracking versus goal tracking in the sexual conditioning of male Japanese quail (Coturnix japonica). J Exp Psychol Anim Behav Process 22:297306.

Burns M, Domjan M (2001) Topography of spatially directed conditioned responding: effects of context and trial duration. J Exp Psychol Anim Behav Process 27:269-278.

Bussey TJ, Everitt BJ, Robbins TW (1997) Dissociable effects of cingulate and medial frontal cortex lesions on stimulus-reward learning using a novel Pavlovian autoshaping procedure for the rat: implications for the neurobiology of emotion. Behav Neurosci 111:908-919.

Cardinal RN, Pennicott DR, Sugathapala CL, Robbins TW, Everitt BJ (2001) Impulsive choice induced in rats by lesions of the nucleus accumbens core. Science 292:24992501.

Cardinal RN, Parkinson JA, Lachenal G, Halkerston KM, Rudarakanchana N, Hall J, Morrison CH, Howes SR, Robbins TW, Everitt BJ (2002) Effects of selective excitotoxic lesions of the nucleus accumbens core, anterior cingulate cortex, and central nucleus of the amygdala on autoshaping performance in rats. Behav Neurosci 116:553-567.

Carelli RM (2000) Activation of accumbens cell firing by stimuli associated with cocaine delivery during self-administration. Synapse 35:238-242.

Carelli RM (2002a) Nucleus accumbens cell firing during goal-directed behaviors for cocaine vs. 'natural' reinforcement. Physiol Behav 76:379-387.

Carelli RM (2002b) The nucleus accumbens and reward: neurophysiological investigations in behaving animals. Behavioral and Cognitive Neuroscience Reviews 1:281-296.

Carelli RM, Deadwyler SA (1994) A comparison of nucleus accumbens neuronal firing patterns during cocaine self-administration and water reinforcement in rats. $\mathrm{J}$ Neurosci 14:7735-7746.

Carelli RM, Wightman RM (2004) Functional microcircuitry in the accumbens underlying drug addiction: insights from real-time signaling during behavior. Curr Opin Neurobiol 14:763-768. 
Carelli RM, Ijames SG, Crumling AJ (2000) Evidence that separate neural circuits in the nucleus accumbens encode cocaine versus "natural" (water and food) reward. J Neurosci 20:4255-4266.

Carelli RM, King VC, Hampson RE, Deadwyler SA (1993) Firing patterns of nucleus accumbens neurons during cocaine self-administration in rats. Brain Res 626:14-22.

Cepeda C, Levine MS (1998) Dopamine and N-methyl-D-aspartate receptor interactions in the neostriatum. Dev Neurosci 20:1-18.

Chang JY, Sawyer SF, Lee RS, Woodward DJ (1994) Electrophysiological and pharmacological evidence for the role of the nucleus accumbens in cocaine selfadministration in freely moving rats. J Neurosci 14:1224-1244.

Chang JY, Zhang L, Janak PH, Woodward DJ (1997) Neuronal responses in prefrontal cortex and nucleus accumbens during heroin self-administration in freely moving rats. Brain Res 754:12-20.

Chang JY, Paris JM, Sawyer SF, Kirillov AB, Woodward DJ (1996) Neuronal spike activity in rat nucleus accumbens during cocaine self-administration under different fixedratio schedules. Neuroscience 74:483-497.

Cromwell HC, Schultz W (2003) Effects of expectations for different reward magnitudes on neuronal activity in primate striatum. J Neurophysiol 89:2823-2838.

Di Chiara G, Bassareo V, Fenu S, De Luca MA, Spina L, Cadoni C, Acquas E, Carboni E, Valentini V, Lecca D (2004) Dopamine and drug addiction: the nucleus accumbens shell connection. Neuropharmacology 47 Suppl 1:227-241.

Di Ciano P, Cardinal RN, Cowell RA, Little SJ, Everitt BJ (2001) Differential involvement of NMDA, AMPA/kainate, and dopamine receptors in the nucleus accumbens core in the acquisition and performance of pavlovian approach behavior. J Neurosci 21:94719477.

Everitt BJ, Wolf ME (2002) Psychomotor stimulant addiction: a neural systems perspective. J Neurosci 22:3312-3320.

Everitt BJ, Robbins TW (2005) Neural systems of reinforcement for drug addiction: from actions to habits to compulsion. Nat Neurosci 8:1481-1489.

Fiorillo CD, Tobler PN, Schultz W (2003) Discrete coding of reward probability and uncertainty by dopamine neurons. Science 299:1898-1902.

Ghitza UE, Fabbricatore AT, Prokopenko VF, West MO (2004) Differences between accumbens core and shell neurons exhibiting phasic firing patterns related to drugseeking behavior during a discriminative-stimulus task. J Neurophysiol 92:16081614. 
Ghitza UE, Prokopenko VF, West MO, Fabbricatore AT (2006) Higher magnitude accumbal phasic firing changes among core neurons exhibiting tonic firing increases during cocaine self-administration. Neuroscience 137:1075-1085.

Gong W, Justice JB, Jr., Neill D (1997) Dissociation of locomotor and conditioned place preference responses following manipulation of GABA-A and AMPA receptors in ventral pallidum. Prog Neuropsychopharmacol Biol Psychiatry 21:839-852.

Goto Y, Grace AA (2005) Dopaminergic modulation of limbic and cortical drive of nucleus accumbens in goal-directed behavior. Nat Neurosci 8:805-812.

Hassani OK, Cromwell HC, Schultz W (2001) Influence of expectation of different rewards on behavior-related neuronal activity in the striatum. J Neurophysiol 85:2477-2489.

Heimer L, Zahm DS, Churchill L, Kalivas PW, Wohltmann C (1991) Specificity in the projection patterns of accumbal core and shell in the rat. Neuroscience 41:89-125.

Hollander JA, Carelli RM (2005) Abstinence from Cocaine Self-Administration Heightens Neural Encoding of Goal-Directed Behaviors in the Accumbens. Neuropsychopharmacology.

Jenkins HM, Moore BR (1973) The form of the auto-shaped response with food or water reinforcers. J Exp Anal Behav 20:163-181.

Kearns DN, Weiss SJ (2004) Sign-tracking (autoshaping) in rats: a comparison of cocaine and food as unconditioned stimuli. Learn Behav 32:463-476.

Kelley AE (1999) Functional specificity of ventral striatal compartments in appetitive behaviors. Ann N Y Acad Sci 877:71-90.

Kelley AE (2004) Ventral striatal control of appetitive motivation: role in ingestive behavior and reward-related learning. Neurosci Biobehav Rev 27:765-776.

Krank MD (2003) Pavlovian conditioning with ethanol: sign-tracking (autoshaping), conditioned incentive, and ethanol self-administration. Alcohol Clin Exp Res 27:1592-1598.

Ljungberg T, Apicella P, Schultz W (1992) Responses of monkey dopamine neurons during learning of behavioral reactions. J Neurophysiol 67:145-163.

Mirenowicz J, Schultz W (1996) Preferential activation of midbrain dopamine neurons by appetitive rather than aversive stimuli. Nature 379:449-451.

Mogenson GJ, Jones DL, Yim CY (1980) From motivation to action: functional interface between the limbic system and the motor system. Prog Neurobiol 14:69-97.

Newlin DB (1992) A comparison of drug conditioning and craving for alcohol and cocaine. Recent Dev Alcohol 10:147-164. 
Nicola SM, Surmeier J, Malenka RC (2000) Dopaminergic modulation of neuronal excitability in the striatum and nucleus accumbens. Annu Rev Neurosci 23:185-215.

Nicola SM, Yun IA, Wakabayashi KT, Fields HL (2004a) Firing of nucleus accumbens neurons during the consummatory phase of a discriminative stimulus task depends on previous reward predictive cues. J Neurophysiol 91:1866-1882.

Nicola SM, Yun IA, Wakabayashi KT, Fields HL (2004b) Cue-evoked firing of nucleus accumbens neurons encodes motivational significance during a discriminative stimulus task. J Neurophysiol 91:1840-1865.

Nicolelis MA, Ghazanfar AA, Faggin BM, Votaw S, Oliveira LM (1997) Reconstructing the engram: simultaneous, multisite, many single neuron recordings. Neuron 18:529-537.

Pan WX, Schmidt R, Wickens JR, Hyland BI (2005) Dopamine cells respond to predicted events during classical conditioning: evidence for eligibility traces in the rewardlearning network. J Neurosci 25:6235-6242.

Parkinson JA, Willoughby PJ, Robbins TW, Everitt BJ (2000) Disconnection of the anterior cingulate cortex and nucleus accumbens core impairs Pavlovian approach behavior: further evidence for limbic cortical-ventral striatopallidal systems. Behav Neurosci 114:42-63.

Parkinson JA, Dalley JW, Cardinal RN, Bamford A, Fehnert B, Lachenal G, Rudarakanchana N, Halkerston KM, Robbins TW, Everitt BJ (2002) Nucleus accumbens dopamine depletion impairs both acquisition and performance of appetitive Pavlovian approach behaviour: implications for mesoaccumbens dopamine function. Behav Brain Res 137:149-163.

Pavlov IP (1927) Conditioned reflexes: An investigation of the physiological activity of the cerebral cortex. Oxford: Oxford University Press.

Paxinos G, Watson C (2005) The rat brain in stereotaxic coordinates, Fifth Edition. New York: El Sevier.

Pennartz CM, Groenewegen HJ, Lopes da Silva FH (1994) The nucleus accumbens as a complex of functionally distinct neuronal ensembles: an integration of behavioural, electrophysiological and anatomical data. Prog Neurobiol 42:719-761.

Peoples LL, Gee F, Bibi R, West MO (1998) Phasic firing time locked to cocaine selfinfusion and locomotion: dissociable firing patterns of single nucleus accumbens neurons in the rat. J Neurosci 18:7588-7598.

Peterson GB, Ackil JE, Frommer GP, Hearst E (1972) Conditioned approach and contact behavior towards signals for food and brain-stimulation reinforcement. Science 177:1009-1011. 
Phillips PE, Stuber GD, Heien ML, Wightman RM, Carelli RM (2003) Subsecond dopamine release promotes cocaine seeking. Nature 422:614-618.

Plenz D (2003) When inhibition goes incognito: feedback interaction between spiny projection neurons in striatal function. Trends Neurosci 26:436-443.

Robbins TW, Everitt BJ (2002) Limbic-striatal memory systems and drug addiction. Neurobiol Learn Mem 78:625-636.

Roitman MF, Wheeler RA, Carelli RM (2005) Nucleus accumbens neurons are innately tuned for rewarding and aversive taste stimuli, encode their predictors, and are linked to motor output. Neuron 45:587-597.

Roitman MF, Stuber GD, Phillips PE, Wightman RM, Carelli RM (2004) Dopamine operates as a subsecond modulator of food seeking. J Neurosci 24:1265-1271.

Schultz W, Apicella P, Ljungberg T (1993) Responses of monkey dopamine neurons to reward and conditioned stimuli during successive steps of learning a delayed response task. J Neurosci 13:900-913.

Setlow B, Schoenbaum G, Gallagher M (2003) Neural encoding in ventral striatum during olfactory discrimination learning. Neuron 38:625-636.

Sidman M, Fletcher FG (1968) A demonstration of auto-shaping with monkeys. J Exp Anal Behav 11:307-309.

Stratford TR, Kelley AE (1999) Evidence of a functional relationship between the nucleus accumbens shell and lateral hypothalamus subserving the control of feeding behavior. J Neurosci 19:11040-11048.

Tomie A, Aguado AS, Pohorecky LA, Benjamin D (1998) Ethanol induces impulsive-like responding in a delay-of-reward operant choice procedure: impulsivity predicts autoshaping. Psychopharmacology (Berl) 139:376-382.

Tomie A, Aguado AS, Pohorecky LA, Benjamin D (2000) Individual differences in pavlovian autoshaping of lever pressing in rats predict stress-induced corticosterone release and mesolimbic levels of monoamines. Pharmacol Biochem Behav 65:509517.

Tomie A, di Poce J, Derenzo CC, Pohorecky LA (2002) Autoshaping of ethanol drinking: an animal model of binge drinking. Alcohol Alcohol 37:138-146.

Uslaner JM, Acerbo MJ, Jones SA, Robinson TE (2006) The attribution of incentive salience to a stimulus that signals an intravenous injection of cocaine. Behav Brain Res 169:320-324. 
Usuda I, Tanaka K, Chiba T (1998) Efferent projections of the nucleus accumbens in the rat with special reference to subdivision of the nucleus: biotinylated dextran amine study. Brain Res 797:73-93.

Wasserman EA (1973) Pavlovian conditioning with heat reinforcement produces stimulusdirected pecking in chicks. Science 181:875-877.

Wilcove WG, Miller JC (1974) CS-USC presentations and a lever: human autoshaping. J Exp Psychol 103:868-877.

Wilson DI, Bowman EM (2004) Nucleus accumbens neurons in the rat exhibit differential activity to conditioned reinforcers and primary reinforcers within a second-order schedule of saccharin reinforcement. Eur J Neurosci 20:2777-2788.

Winstanley CA, Baunez C, Theobald DE, Robbins TW (2005) Lesions to the subthalamic nucleus decrease impulsive choice but impair autoshaping in rats: the importance of the basal ganglia in Pavlovian conditioning and impulse control. Eur J Neurosci 21:3107-3116.

Wise RA (1998) Drug-activation of brain reward pathways. Drug Alcohol Depend 51:13-22.

Wise RA (2004) Dopamine, learning and motivation. Nat Rev Neurosci 5:483-494.

Yun IA, Wakabayashi KT, Fields HL, Nicola SM (2004) The ventral tegmental area is required for the behavioral and nucleus accumbens neuronal firing responses to incentive cues. J Neurosci 24:2923-2933. 